Borneo Journal of Sciences \& Technology, Volume (3), Issue (1), Pages: 21-28

DOI: http://doi.org/10.3570/bjost.2021.3.1-04

e-ISSN: 2672-7439

(C) 2018, UCTS Publisher.

Submitted: $20^{\text {th }}$ February $2020 \quad$ Accepted: $15^{\text {th }}$ August $2020 \quad$ Published: $31^{\text {st }}$ January 2021

\title{
The Validity of the Microsoft Kinect for Healthy Participants: A Short Review
}

\author{
${ }^{1}$ Ivan Lau Yong Sing, ${ }^{1}$ Ting Huong Yong and ${ }^{2}$ Toh Teck Hock \\ ${ }^{1}$ School of Computing and Creative Media, University College of Technology Sarawak (UCTS), \\ 96000 Sibu Sarawak, Malaysia \\ ${ }^{2}$ Clinical Research Centre, Sibu Hospital, 96000 Sibu Sarawak, Malaysia
}

\begin{abstract}
The Microsoft Kinect is a motion sensor input tool that swiftly infected in physical therapy training. Kinect have several advantages over traditional solutions which currently they are in a very affordable situation. Moreover, their accuracy for sensitive human application is still under analysis. This short review provides a summary of the validity of the Kinect sensor to comprehend their usefulness as a measurement tool for practical analysis applications. The results are challenging to compare because they depend to a huge level on the type of measurement element, the variety of human motion, and the distance of the sensor. Regardless of this, they think that the Kinect appropriately identifies motion, however, does not recognise joint rotation and different posture.
\end{abstract}

Keywords: Healthy Participants, Microsoft Kinect, Review, and Validity

\section{INTRODUCTION}

Motion Capture (Mocap) is a process performed by a variety of methods that can be utilised for a vast array of research tools to measuring and recording the position of the human body throughout the exercise [1]. Depth-based optical technology (RGB-D) is one of the methods used to recognise human body position. Usually, a set of markers is attaching at the human body and triangulating images are extracted from different cameras to capture human motion. The uses of RGB-D accomplish the similar task and measuring the distance between the individual and the sensor, such as, depth of the scene. The infrared light projection will help to invariant the colour under low lighting [2]. RGB-D avoid the use of marker because it makes participant feel uncomfortable and slow process in capture process.

Moreover, RGB-D has been used for these recent years because it is inexpensive in price, convenience to carry, and functionality with the launch of Microsoft Kinect sensor [3]. Consequently, they typically used as a referral for examining the usefulness of RGB-D for human motion evaluation applications, such as, posture $[4,5,6]$, gait analysis $[7,8,9]$, motion recognition and analysis $[10,11,12,13,14]$, and other relevant motion capture. The purpose of this paper is to briefly review recent studies on the validity of the Kinect sensor in practical assessment applications to comprehend their feasibility as a measurement tool.

\section{The Microsoft Kinect}

The Microsoft Kinect has two generations; the first generation of Kinect (Kinect 1.0) was released in 2010 and currently is a dynamic camera which dissimilar from human control tools in Sony or Nintendo and other brands. It enables the individual to play without having to carry any type of devices used only gesture and voice only. The Kinect is an inexpensive sensor that measures information in real-time by triangulation, record RGB and IR images at the structure rates approximately $30 \mathrm{fps}$. It includes an RGB camera, an infrared-based projector, an infrared camera, a tilt, a microphone, and a 3-axis accelerometer [15].

Kinect 1.0 makes use of structured light technology to measure the distance [16]. The observation quantity is parallax which represents the balances mode to match the model recommended pattern by the IR camera recorded. The major negative aspect of Kinect 1.0 is the low geometric data transmitted quality, low noise, and low reproducibility [15].

Besides, Kinect 1.0 registered poor-quality depth data because structured light technique insufficient to deliver high stability of structure scene. Meanwhile, the information extracted from normal stepped is always with missing section and very noise [17].

The second generation of Kinect (Kinect 2.0) launched in 2013 to make available of high-quality images and quality depth data. It provides better depth

Corresponding Author: Ting Huong Yong, University College of Technology Sarawak (UCTS),

E-mail: alan.ting @ucts.edu.my 
measurements for more precise skeletal monitoring and motion recognition. Both generation of Kinect has an equal number of the sensor, but the depth is determined using an entirely different measurement concept [17]. However, Microsoft Kinect has its advantages and imperfection that are being analysed to specify in their availability in the real-world situation. Hence, the studies of Microsoft Kinect in a real situation is an interesting study to be review.

\section{LITERATURE REVIEW}

$\mathrm{Xu}$, et al., [18] accomplished three traits treadmill which the participants have to walk at three different walking speeds randomly in five minutes and two minutes break in between each trait. The data for the feet, upper and lower legs, and pelvis during walking is collected during each walking. The outcomes reveal that the use of the Kinect sensor differs with gait parameters. All participants have the average hell strike structure error for the right $(0.18)$ and left $(0.30)$ feet and ordinary toe-off was -2.25 and -2.61 . The time of the gait parameter on strike has less error compared to the time of gait parameter on toe-off. Besides, the Kinect sensor complies with the movement of the joint trajectory of knee and hip joint, although there is a significant error in amplitude. It has been found that walking speed is significant influences the time of toeoff. The authors concluded that the Kinect might use as an alternative tool for determining several of gait parameters for treadmill walking between healthy and pathological group. In sum, the authors suggest that Kinect sensor cannot be used for clinical gait analysis for knee and joint angles.

Mentiplay, et al., [19] performed Gail trials with $8 \mathrm{~m}$ from Kinect and each participant performed gait trail in both comfortable and fast-paced. The evaluation of the trial is based on each step of successful contact to analyse the scientific feasibility of Kinect. Ankle flexion, hip flexion angles, and knee flexion and adduction were studied as the kinematic variables. Pearson's (r) were used to compute the relative agreement in this study. The result shows that the deprived relative consistency for all kinematic variables $(\mathrm{r}<0.4)$, besides the comfortable pacing hip flexion $(\mathrm{r}$ $=0.49$ ). In addition to the excellent outcomes ( $\mathrm{rc}>$ 0.75 ) of gait speed for spatiotemporal variables. In summary, Kinect V2 is a low-cost and portable device for evaluating the spatial-temporal and component of gait, unfortunately, it may be suitable for lower body kinematic data.

Dolatabadi et al., [20] measured the validity of Microsoft Kinect V2 for spatiotemporal gait parameters. The data collection of each participant included three walking conditions which is fast pace, usual pace, and dual-task. The time for stance and step, length for step, velocity for gait were recorded by Kinect v2 sequences to extracted various spatiotemporal features. To determine the agreement, Bland-Altman Limit of Agreement method and the Intraclass Correlation Coefficient (ICC) was adopted. Additionally, the outcomes indicate that the $95 \%$ of the Bland-Altman Limit is narrow enough and achieved an excellent ICC2,1 in 0.9 to 0,98 and ICC 3,1 in 0.73 which concluded that the Kinect v2 could be a reliable instrument to measuring gait time and space parameters reported in this study for healthy adults.

Eltoukhy et al., [21] was to determine the validity of Kinect v2 in kinematic and spatiotemporal parameters of gait analysis in a treadmill. Each participant was requested to practice walking with two testing speeds which are 1.3 and $1.6 \mathrm{~ms}-1$. The data for Kinematic variable includes hip, knee, and ankle; besides, the data for Spatiotemporal includes length and width of step, time for stripe and step, pelvis displacement in mediolateral and vertical, and velocity while foot swing. The Concordance Correlation Coefficients was employed to obtain absolute agreement. It is statistically significant in correlation coefficients for the hip and knee $(0.73<\mathrm{r}<0.77)$. Overall, the authors concluded that the Kinect could be a reliable scientific instrument for analysing hip and knee kinematics and spatiotemporal variables in walking gait.

Vilas-Boas et al., [22] assessed the validity of Kinect for full-body motion assessment. The participant is required to perform their comfortable pace in ten gait trails and each trail included walking towards and walking away for $14 \mathrm{~m}$. It is worth mentioning that Vilas-Boas study had analysed the upper body angles during gait. Consequently, the velocity of 20 joints, the distance between symmetrical joints, and the angle at the specific joint was the data collected by Kinect and measured by the KinecTracker software. The data was used to compute some statistical analysis, such as, Pearson's correlation coefficient, optical-to-depth ratio, and some other statistical analysis. The walking through data achieved the best result for velocity measures. For the distance measurement, all the mean optical-to-depth values are higher than other measurements. Meanwhile, the distance measurement achieve excellent results for all considered body segment. Furthermore, the measurement of the joint angles scored the poor results compared with other measures. Although Vilas-Boas and the group evaluated the upper body angles during gait, yet that was only knee angle assessed significant result. In sum, the finding indicated that the Kinect could be an alternative tool for intrusive reference system for velocity measurement and distance measurement.

Clark et al., [23] performed the validity and reliability of Kinect of assessing static standing balance 
test and dynamic standing balance test. Vicon camera, specifically, Three-Dimensional Motion Analysis (3DMA) system was applied as a reference. Static standing balance test was performed to evaluate singlelimb standing and double limb standing with eyes open and eyes closed. Dynamic standing balance test evaluates forward and lateral reach movements and limits of stability assessment from a straight posture which participants were correctly moving in a specific position. The assessment of static and dynamic balance was compared between Kinect and 3DMA system. Their results indicated excellent validity of dynamic balance based on the assessment of limits of stability test and all measurements of anterior-posterior range and path length for all static balance trials. However, the validity and reliability of the medial-lateral range and path length were poor except single-leg closed eyes. The authors concluded that the Kinect has the potential to be used as a reliable and valid tool for assessment of some aspect of balance performance. However, more validation research for the mediallateral range is needed.

Huber et al., [24] assessed the reliability and validity of the shoulder joint angle from Kinect for virtual rehabilitation. They performed a set of tests involving various shoulder angles. The results were compared with a goniometer analysis to ensure reliability and validity. Kinect captured both the frontal view and sagittal view. The frontal view captures the measure of shoulder angle in four poses which consists flexion to $90^{\circ}$, flexion to the max, abduction to $90^{\circ}$, and external rotation to the max at $0^{\circ}$ abduction. The sagittal view captures the two poses of shoulder flexion measure. The reliability of the Kinect of shoulder angle measurement was determined by the Intraclass Correlation Coefficient, Standard Error of the Measure, and Minimal Detectable Changes. Based on the results, Intraclass Correlation Coefficient indicated Kinect had relative reliability for the frontal view shoulder angle measurement for all four poses, however, flexion to $90^{\circ}$ and external rotation to the max at $0^{\circ}$ abduction was not reliable for the measurement of Standard Error of the Measure values and Minimal Detectable Changes values. An interesting facet of this study is that from the sagittal view, Kinect had absolute reliability in the flexion to $90^{\circ}$ pose. Therefore, the authors concluded that the shoulder angle measure by the Kinect was inaccurate.

Oh et al., [25] performed spatiotemporally and kinematics with Kinect, using Three Dimensional Motion Analysis as a reference. All subjects were required to ascend and descend the stairs to perform the experiment. Both systems were used to obtain all results and compared using t-tests to identify significant between systems. Based on the result, the analysis of spatiotemporal was significant between systems.
Besides, the result shown the ankle kinematics assessment were not significant between systems. The authors concluded that the Kinect was the valid and reliable measurement of selected hip and knee kinematics and spatiotemporal during ascent and descent of stair.

Roy et al., [26] pointed out the joint coordinates of human lower extremity identified by Kinect and Goniometer used as a reference. Left knee angle, right knee angle, left hip flexion, and right hip flexion, the lumbar extension was chosen for the gait analysis. The joint angle movement was calculated from the raw Three Dimension Coordinates System and the calculated angle values were recognised by OpenSim as valid input. Joint angle bending with gait speed were recorded and analysed to identify its relationship. Based on the result, the relationship of angular gait data and speed of motion is determined with respect between Kinect and Goniometer. Hence, the accuracy of Kinect was comparable to the Goniometer.

Auvinet et al., [27] evaluated the validity and sensitivity of the longitudinal asymmetry index using Kinect to detect gait asymmetry and Vicon system as a reference. A group of healthy subjects were asked to walk at the self-selected comfortable speed at three walking trails on a treadmill. One with a normal gait and two with artificially asymmetrical gaits on a treadmill. Four hypotheses were proposed to evaluate the validity and sensitivity of the longitudinal asymmetry index to detect gait asymmetry. Hypothesis 1 confirmed the constant relative phase computed with Kinect data is not reliable, which lead to a great interest in designing longitudinal asymmetry with Kinect. Hypothesis 2 shown longitudinal asymmetry with Kinect was able to detect asymmetrical gaits across almost all asymmetrical cycle. Hypothesis 3 confirmed the placement of Kinect sensors has a low impact on the sensitivity and validity of longitudinal asymmetry with Kinect. Hypothesis 4 illustrated gait cycles lead to reliable longitudinal asymmetry with Kinect. In sum, the results proved the position of the sensor had no strong influence, small gait cycle is enough to detect gait asymmetry, the reliable assessment of longitudinal asymmetry index can be implemented based on depth images, and it is suggested to provides as an alternate clinical tool for gait asymmetry assessment.

Napoli et al., [28] performed twelve movements for head, spine, shoulder, elbow, wrist, hand, hip, knee, ankle, and foot along with the mediolateral, vertical, and anteroposterior plane, using a Qualisys motion capture system. Their results indicated consistent of cross-correlation values and average absolute errors between systems. The ideal value of cross-correlation was close to one and the root means squared error value was close to zero. The overall analysis shows that some segments or joints were tracked with less accuracy, 
especially foot and ankle. Among the cardinal planes, mediolateral direction achieved the most accurate level. Besides, alternating barbell lungs and combined arm adduction had the lowest performance and largest errors for the motion tracking accuracy. In conclusion, Kinect can be a viable alternative to professional threedimension capture system for some applications.

Tanaka et al., [29] assessed the validity of the Kinect for the gait assessment with the healthy subject, using a Vicon system as reference. They performed a set of tests to obtained kinematic data of gait analysis. The results were compared with a Vicon to ensure validity. Kinect captured both the frontal view and sagittal view. Both views captured the projection angle of the knee and hip joints. The results showed the largest differences for hip joint sagittal view between both systems was $4.2^{\circ}$ and hip joint frontal view was less than $5^{\circ}$. For knee joint results were presented a difference of $5.8^{\circ}$ for sagittal view and a difference of $1.5^{\circ}$ for frontal view. The differences angles between system were acceptable for gait analysis. Therefore, the authors concluded that the Kinect time series kinematic data were validated by the Vicon.

Wochatz et al., [30] used Microsoft Kinect assessing a set of dynamic joint lower extremity kinematics tests, with a Three Dimension Motion System as reference. The kinematics of lower limb consisting of landmarks and joint angles capture by Kinect during squat, hip abduction, and lunge exercises.
The joint angle was derived in frontal and sagittal view for both hip angle and knee angle. Besides, limits of agreement and standard error of measurement were calculated to assess the reliability of Kinect system bias. Authors interpreted their results for joint angles and position during the squat as good with the parameters of $\mathrm{r}$ ranged from 0.18 to 0.83 specifying significant expect knee flexion movement at initiation and two knee position. For the lunge exercise, the $r$ range of the front leg is 0.01 to 0.83 , and the $r$ range of the hind leg is 0.15 to 0.80 , which is significantly correlated with baseline and maximum knee and hip flexion. A significant correlation for hip abduction exercise which the standing leg scored $\mathrm{r}$ ranged from 0.06 to 0.062 for knee and hip angles and the moving leg scored $\mathrm{r}$ ranged from 0.16 to 0.59 at both baseline and maximum excursion. On the other hand, Kinect assessed some joint angles were lower than the Vicon system. In summary, the increasing complexity of the movement decreased the reliability of the Kinect system yet Kinect was reliably assessed lower limb kinematic for simple movement.

\section{DISCUSSION}

The validation of the results is used to ensure the uses of Microsoft Kinect in human health. The related research is extensive and proposed interesting results to comprehends and the outlines of studies discussed in this review is presented in Table 1.

Table 1: Summaries of Past Studies

\begin{tabular}{|c|c|c|c|c|c|}
\hline Paper & Technology & Distance & Participants & Tests & $\begin{array}{c}\text { Authors' summary } \\
\text { toward Kinect }\end{array}$ \\
\hline $\mathrm{Xu}$ et al., [18] & $\begin{array}{l}\text { Microsoft } \\
\text { Kinect: Kinect } \\
\text { sensor }\end{array}$ & $\begin{array}{l}\text { Three } \\
\text { trials of } \\
\text { treadmill } \\
\text { walking }\end{array}$ & $\begin{array}{l}20 \text { Healthy } \\
\text { Participants }\end{array}$ & Treadmill Walking & $\begin{array}{l}\text { Accuracy levels are } \\
\text { varied across the gait } \\
\text { parameters. }\end{array}$ \\
\hline $\begin{array}{l}\text { Mentiplay et } \\
\text { al., [19] }\end{array}$ & $\begin{array}{l}\text { Microsoft } \\
\text { Kinect V2: } \\
\text { Body tracking } \\
\text { system / } \\
\text { Kinematic }\end{array}$ & $8 \mathrm{~m}$ & $\begin{array}{l}30 \text { Healthy } \\
\text { Adults }\end{array}$ & $\begin{array}{l}\text { Flexion for ankle, } \\
\text { knee, adduction and } \\
\text { hip }\end{array}$ & $\begin{array}{l}\text { Not accurately acquire } \\
\text { lower body kinematic } \\
\text { data. A potential tool } \\
\text { for spatiotemporal } \\
\text { aspects of gait. }\end{array}$ \\
\hline $\begin{array}{l}\text { Dolatabadi et } \\
\text { al., [20] }\end{array}$ & $\begin{array}{l}\text { Microsoft } \\
\text { Kinect V2: } \\
\text { Kinect Sensor }\end{array}$ & $4.5 \mathrm{~m}$ & $\begin{array}{l}20 \text { Healthy } \\
\text { Adults }\end{array}$ & $\begin{array}{l}\text { Time for stance and } \\
\text { step, length for step, } \\
\text { and velocity of gait }\end{array}$ & $\begin{array}{l}\text { Capacity to measure } \\
\text { some spatiotemporal } \\
\text { gait parameters for } \\
\text { healthy adults. }\end{array}$ \\
\hline $\begin{array}{l}\text { Eltoukhy et al., } \\
\text { [21] }\end{array}$ & $\begin{array}{ll}\text { Microsoft } \\
\text { Kinect V2: } \\
\text { Kinect Sensor }\end{array}$ & $2.5 \mathrm{~m}$ & $\begin{array}{l}\text { Ten Healthy } \\
\text { Adults }\end{array}$ & $\begin{array}{lr}\text { Hip } & \text { kinematic } \\
\text { variables, } & \text { knee } \\
\text { kinematic } & \text { variables, } \\
\text { ankle } & \text { kinematic } \\
\text { variables, step (length, } & \text { width and time), pelvic } \\
\text { displacement } & \text { (medio } \\
\text { lateral and } & \text { vertical), }\end{array}$ & $\begin{array}{l}\text { Potentially to be an } \\
\text { operational clinical } \\
\text { instrument } \\
\text { assessing for } \\
\text { plane knee and hip } \\
\text { joint kinematics and } \\
\text { some spatiotemporal } \\
\text { variables. }\end{array}$ \\
\hline
\end{tabular}


The Validity of the Microsoft Kinect for Healthy Participants: A Short Review

\begin{tabular}{|c|c|c|c|c|c|}
\hline & & & & $\begin{array}{l}\text { stride time, and } \\
\text { velocity for foot swing }\end{array}$ & \\
\hline $\begin{array}{l}\text { Vilas-Boas et } \\
\text { al., [22] }\end{array}$ & $\begin{array}{l}\text { Microsoft } \\
\text { Kinect: } \\
\text { KinecTracker } \\
\text { (KiT) software } \\
\text { application }\end{array}$ & $14 \mathrm{~m}$ & $\begin{array}{l}20 \text { Healthy } \\
\text { Adults }\end{array}$ & $\begin{array}{l}\text { Posture and balance, } \\
\text { gait, movement-related } \\
\text { diseases, rehabilitation, } \\
\text { and joint position } \\
\text { estimation }\end{array}$ & $\begin{array}{l}\text { Alternative to more } \\
\text { expensive tools for } \\
\text { obtaining distance and } \\
\text { velocity measures and } \\
\text { knee angles. }\end{array}$ \\
\hline $\begin{array}{l}\text { Clark et al., } \\
{[23]}\end{array}$ & $\begin{array}{l}\text { Microsoft } \\
\text { Kinect v2 }\end{array}$ & $2.5 \mathrm{~m}$ & $\begin{array}{l}30 \text { Healthy } \\
\text { Adults }\end{array}$ & $\begin{array}{l}\text { Standing balance and } \\
\text { postural control }\end{array}$ & $\begin{array}{l}\text { It is a reliable tool to } \\
\text { assess some aspects of } \\
\text { balance performance }\end{array}$ \\
\hline $\begin{array}{l}\text { Huber et al., } \\
{[24]}\end{array}$ & $\begin{array}{l}\text { Kinect: Three- } \\
\text { dimensional } \\
\text { motion system }\end{array}$ & - & $\begin{array}{l}10 \text { Healthy } \\
\text { Adults }\end{array}$ & $\begin{array}{l}\text { Shoulder joint angle: } \\
\text { abduction to } 90^{\circ} \text {, } \\
\text { external rotation to } \\
\text { max at } 0^{\circ} \text { abduction, } \\
\text { flexion to } 90^{\circ} \text {, flexion } \\
\text { to max }\end{array}$ & $\begin{array}{l}\text { Kinect was inaccurate } \\
\text { to measure the } \\
\text { shoulder angle. }\end{array}$ \\
\hline Oh et al., [25] & $\begin{array}{l}\text { Microsoft } \\
\text { Kinect V2: } \\
\text { Kinect Sensor }\end{array}$ & $\begin{array}{l}\text { Three step } \\
\text { staircases } \\
\text { with } \\
20 \mathrm{~cm} \text { step } \\
\text { height, } \\
25 \mathrm{~cm} \\
\text { depth, } \\
8 \mathrm{~cm} \\
\text { width }\end{array}$ & $\begin{array}{l}12 \text { Healthy } \\
\text { Adults }\end{array}$ & $\begin{array}{l}\text { Spatiotemporal and } \\
\text { kinematics analysis }\end{array}$ & $\begin{array}{l}\text { Kinect may become } \\
\text { an effective clinical } \\
\text { assessment for hip and } \\
\text { knee kinematics and } \\
\text { certain spatiotemporal } \\
\text { parameters in gait }\end{array}$ \\
\hline Roy et al., [26] & $\begin{array}{ll}\text { Microsoft } & \\
\text { Kinect } & \text { v1 } \\
\text { Sensor } & \end{array}$ & $1.8 \mathrm{~m}$ & $\begin{array}{l}10 \text { Healthy } \\
\text { Adults }\end{array}$ & $\begin{array}{l}\text { Joint coordinates of a } \\
\text { lower extremity of a } \\
\text { human }\end{array}$ & $\begin{array}{l}\text { Microsoft camera was } \\
\text { reliable to capture } \\
\text { subject motions. }\end{array}$ \\
\hline $\begin{array}{l}\text { Auvinet et al., } \\
{[27]}\end{array}$ & $\begin{array}{l}\text { Microsoft } \\
\text { Kinect: } \\
\text { Longitudinal } \\
\text { asymmetry } \\
\text { index }\end{array}$ & $\begin{array}{l}\text { Three } \\
\text { trials of } \\
\text { treadmill } \\
\text { walking }\end{array}$ & $\begin{array}{l}15 \text { Healthy } \\
\text { Adults }\end{array}$ & Gait asymmetry & $\begin{array}{l}\text { Longitudinal } \\
\text { asymmetry index is an } \\
\text { alternative clinically } \\
\text { pragmatic method for } \\
\text { gait asymmetry } \\
\text { assessment. }\end{array}$ \\
\hline $\begin{array}{l}\text { Napoli et al., } \\
{[28]}\end{array}$ & $\begin{array}{l}\text { Microsoft } \\
\text { Kinect V2: } \\
\text { Kinect Sensor }\end{array}$ & 2 to $4 \mathrm{~m}$ & $\begin{array}{l}\text { Four Healthy } \\
\text { Adults }\end{array}$ & $\begin{array}{l}\text { Body joint placements } \\
\text { and body joint angles }\end{array}$ & $\begin{array}{l}\text { Kinect is a practical } \\
\text { tool for general } \\
\text { biomechanical } \\
\text { research. }\end{array}$ \\
\hline $\begin{array}{l}\text { Tanaka at el., } \\
{[29]}\end{array}$ & $\begin{array}{ll}\text { Microsoft } \\
\text { Kinect V2: } \\
\text { Kinect sensor }\end{array}$ & $8 \mathrm{~m}$ & $\begin{array}{l}51 \text { Healthy } \\
\text { Adults }\end{array}$ & $\begin{array}{l}\text { Hip and knee joint } \\
\text { angles }\end{array}$ & $\begin{array}{l}\text { The kinematical data } \\
\text { obtained were valid } \\
\text { nevertheless, } \\
\text { reproducibility and } \\
\text { systematic bias of } \\
\text { Kinect is needed to be } \\
\text { examined in future. }\end{array}$ \\
\hline $\begin{array}{l}\text { Wochatz et al., } \\
{[30]}\end{array}$ & $\begin{array}{l}\text { Microsoft } \\
\text { Kinect V2 }\end{array}$ & $2.5 \mathrm{~m}$ & $\begin{array}{l}21 \text { Healthy } \\
\text { Adults }\end{array}$ & $\begin{array}{ll}\text { Lower } & \text { extremity } \\
\text { kinematics } & \end{array}$ & $\begin{array}{l}\text { Kinect is reliable for } \\
\text { lower limb kinematics } \\
\text { analysis of simple } \\
\text { exercises, yet the } \\
\text { validity of the system } \\
\text { was restricted. }\end{array}$ \\
\hline
\end{tabular}

Eltoukhy et al., [21] which they claim Kinect is an effective tool for knee joint kinematic and positioned the camera directly in front of the area with $0.75 \mathrm{~m}$ height. Conversely et al., [27] confirmed the placement of Kinect has a low impact on the sensitivity and validity of longitudinal asymmetry with Kinect. The 
positioning of the Kinect was deeply investigated by most of the researchers. Xu et al., [18] confirmed that when the position of the Kinect is less easy to observe in certain part the consequential gait was expected to be additional inaccurate. Dolatabadi et al., [20] highlighted that the placement of the Kinect at dissimilar locations and distance from the subject should be scrutinised and the potential error should be stated. Also, Mentiplay, et al. (2015) [19] emphasised the distance from the Kinect was exceptional and without obvious effect to measure spatiotemporal aspects of gait. Nevertheless, VilasBoas, Choupina et al., [22] which they claim that for the distance for mean approximation errors are between one and eleven centimetres and may be adequate for some request. These drawn the assumption that the placement of the Kinect was important as it influenced the finding of the research.

Moreover, the Kinect was suggested by most of the studies as a potential clinical assessment for certain analysis. For example, Mentiplay, et al., [19] was good in evaluating the spatial-temporal and component of gait, yet it is suitable for lower body kinematic data. This was further supported by Tanaka et al., [29] emphasised the kinematical analysis conducted by Kinect was valid if appropriate correction are performed. Which Eltoukhy et al., [21] suggested Kinect to be used as an operational clinical instrument for assessing sagittal plane knee and hip joint kinematics and some spatiotemporal variables. Conversely et al., [18] emphasised that Kinect can be an alternative tool for determining several of gait parameters for treadmill walking between the healthy and pathological group, yet it cannot be used for clinical gait analysis for knee and joint angles. Also, Wochatz et al., [30] confirmed the Kinect was reliable for lower limb joint angle of simple exercise at the early stage of orthopaedic rehabilitation yet it is not advised to use as a clinical tool. Additionally, Dolatabadi et al., [20] reported that Kinect is capable of measuring some spatiotemporal gait parameters for healthy adults. These concluded that Kinect was suitable for specific analysis in human motion for healthy adults and it could be an alternative for an expensive clinical assessment tool.

The assessment of kinematics and spatiotemporal evaluated by stair ascent and the descent was conducted by Oh et al., [25]. Oh and the research team suggested Kinect become an effective clinical assessment for hip and knee kinematics and certain spatiotemporal parameters in gait. This short review highlighted that the placement of Kinect sensor was important because it impacts the validity of assessment with Kinect. Besides, Kinect was an excellent tool to capture human motion. However, Kinect was recommended as an alternation for clinical assessment tool with certain specification.
Vilas-Boas et al., [22] suggested that Kinect can be an alternative system to measures velocity and distance and recommended to reassessed for the joint angle. This was supported by Huber et al., [24] which Kinect had poor results for the measurement of shoulder angle. Conversely, research conducted by Roy [26] highlighted that Kinect helps to derived certain body joint angles specifically the angle data of five prominent lower limb section was comparable to Goniometer. Napoli et al., [28] also highlighted that Kinect was adequate for tracking joint centre displacements but it is less accuracy of tracking joint angle. These considerations imply that measurement of joint angles for healthy adult required further research to ensure the validity of Kinect.

Clark et al., [23] concluded that the measurement of anterior-posterior displacement can be confidently obtained for double leg tasks, yet it was inadequate for single lag tasks. This concluded that Kinect only validated for two-legged balancing performance.

\section{CONCLUSION}

This short review summarises some studies that particularly attend to the validity of the Microsoft Kinect sensor which highlighting their practical analysis. Most of the researchers believe that the Microsoft Kinect sensor is an indisputable system, in term of cost and sizes is less than a laptop. Perhaps, the most attractive benefits are they are easy to use and using less time to gain human body data. These provide excellent potential for Microsoft Kinect in human motion recognition. Additionally, the outcomes acquired by the study suggest that the sensor, especially the Kinect v2 is accomplished of recognising the motion of the human body with adequate accuracy. Alternatively, the outcomes suggest that the validity of Kinect is highly dependent on the specific application. Furthermore, the human motion of specific analysis in clinical assessment is recommended as the results showed a positive analysis in healthy adults. The application of Kinect in clinical could comparable to the traditional system because it is small with a significant advantage.

\section{REFERENCES}

[1] Kruk, E. V. \& Reijne, M. M. 2018. Accuracy of human motion capture systems for sport applications; state-of-the-art review. European Journal of Sport Science, 18(6), 806-819.

[2] Diaz-Monterrosas, P. R., Posada-Gomez, R., Martinez-Sibaja, A., Aguilar-Lasserre, A. A., Juarez-Martinez, U., \& Trujillo-Caballero, J. C. 2018. A brief review on the validity and reliability of Microsoft Kinect Sensor for functional 
assessment applications. Advances in Electrical and Computer Engineering, 18(1), 131-136.

[3] Smith, L. N., Zhang, W., Hansen, M. F., Hales, I. J., \& Smith, M. L. 2018. Innovative 3D and 2D machine vision methods for analysis of plants and crops in the field. Computers in Industry, 97, 122131.

[4] Castro, A., Pacheco, J., Lourenco, C., Queiros, S., Moreira, A., Rodrigues, N., \& Vilaca, J. 2017. Evaluation of spinal posture using microsoft kinect: A prelimenary case-study with 98 volunteers. Porto Biomediacal Journal, 2(1), 18-22.

[5] Darby, J., Sanchez, M., Butler, P., \& Loram, I. 2016. An evaluation of 3D head pose estimation using the Microsoft Kinect V2. Gait and Posture, 48, 83-88.

[6] Ho, E., Chan, J., Chan, D., Shum, H., Cheung, Y.m., \& Yuen, P. C. 2016. Improving posture classification accuracy for depth sensor-based human activity monitoring in smart environment. Computer Vision and Image Understanding, 148, 97-110.

[7] Dubois, A. \& Bresciani, J.-P. 2018. Validation of an ambient system for the measurement of gait parameters. Journal of Biomechanics, 69, 175-180.

[8] Jebeli, M., Bilesan, A., \& Arshi, A. 2017. A study on validating Kinect V2 in comparison of Vicon system as a motion capture system for using in health engineering in industry. Nonlinear Engineering, 6(2), 95-99.

[9] Clark, R. A., Bower, k. J., Mentiplay, B. F., Paterson, K., \& Pua, Y. H. 2013. Concurrent validity of the Microsoft Kinect for assessment of spatiotemporal gait variables. Journal of Biomechanics, 46, 2722-2725.

[10] Pang, X. \& Liang, B. 2019. Motion recognition based on kinect for human-computer intelligent interaction. Journal of Physics, 1187, 1-7.

[11] Bilesan, A., Owlia, M., Behzadipour, S., Ogawa, S., Tsujita, T., Komizunai, S., \& Konno, A. 2018. Marker-based motion tracking using Microsoft Kinect. IFAC PaperOnLine, 51(22), 399-404.

[12] Giancola, S., Corti, A., Molteni, F., \& Sala, R. 2017. Motion capture: An evaluation of kinect v2 body tracking for upper limb motion analysis. 6th EAI International Conference on Wireless Mobile Communication and Healthcare, (pp. 302-309). Milan, Italy.

[13] Blumrosen, G., Miron, Y., Intrator, N., \& Plotnik, M. 2016. A real-time Kinect signature-based patient home monitoring system. Sensor, 16(11), 1965.

[14] Zerpa, C., Lees, C., Patel, P., \& Pryzsucha, E. 2015. The use of microsoft kinect for human movement analysis. International Journal of Sport Science, 5(4), 120-127.
[15] Pagliari, D., Menna, F., Roncella, R., Remondino, F., \& Pinto, L. 2014. Kinect fusion improvement using depth camera calibration. The International Archives of the Photogrammetry, Remote Sensing and Spatial Information Sciences, 40(5), 479-485.

[16] Lindner, M., Schiller, I., Kolb, A., \& Koch, R. 2010. Time-of-Flight sensor calibration for accurate range sensing. Computer Vision and Image Understanding, 114(12), 1318-1328.

[17] Pagliari, D. \& Pinto, L. 2015. Calibration of Kinect for Xbox one and comparison the two generations of Microsoft sensors. Sensors, 15, 27569-27589.

[18] Xu, X., McGorry, R. W., Chou, L. S., Lin, J. H., \& Chang, C. C. 2015. Accuracy of the Microsoft Kinect for measuring gait parameters during treadmill walking. Gait and Posture, 42, 145-151.

[19] Mentiplay, B. F., Perraton, L. G., Bower, K. J., Pua, Y. H., McGaw, R., Heywood, S., \& Clark, R. A. 2015. Gait assessment using the Microsoft Xbox One Kinect: Concurrent validity and interday reliability of spatiotemporal and kinematic variables. Journal of Biomechanics, 48, 21662170.

[20] Dolatabadi, E., Taati, B., \& Mihailidis, A. 2016. Concurrent validity of the Microsoft Kinect for Windows v2 for measuring spatiotemporal gait parameters. Medical Engineering and Physics, 38(9), 952-958.

[21] Eltoukhy, M., Oh, J., Kuenze, C., \& Signorile, J. 2017. Improved kinect-based spatiotemporal and kinematic treadmill gait assessment. Gait and Posture, 51, 77-83.

[22] Vilas-Boas, M. C., Choupina, H. M., Rocha, A. P., Fernandes, J. M., \& Chunha, J. P. 2019. Full-body motion assessment: Concurrent validation of twobody tracking depth sensors versus a gold standard system during gait. Journal of Biomechanics, 87, 189-196.

[23] Clark, R., Pua, Y., Oliveira, C., Bower, K. J., Thilarajah, S., McGaw, R., Hasanki, K., \& Mentiplay, B. F. 2015. Reliability and concurrent validity of the microsoft kinect v2 for assessment of standing balance and postural control. Gait and Posture, 42(2), 210-213.

[24] Huber, M., Seitz, A., Leeser, M., \& Sternad, D. 2015. Validity and reliability of kinect skeleton for measuring shoulder joint angles: A feasibility study. Physiotherapy, 101(4), 389-393.

[25] Oh, J., Kuenze, C., Jacopetti, M., Signorile, J. F., \& Eltoukhy, M. 2018. Validity of the microsoft kinect in assessing spatiotemporal and lower extremity kinematics during staia ascent and descent in healthy young individuals. Medical Engineering and Physics, 60, 70-76.

[26] Roy, G., Bhuiya, A., Mukherjee, A., \& Bhaumik, S. 2018. Kinect camera based gait data recording 
and analysis for assistive robotics: An alternative to goniometer based measurement technique. Procedia - Computer Science, 133, 763-771.

[27] Auvinet, E., Multon, F., Manning, V., Meunier, J., \& Cobb, J. 2017. Validity and sensitivity of the longitudinal asymmetry index to detect gait asymmetry using microsoft kinect data. Gait and Posture, 51, 162-168.

[28] Napoli, A., Glass, S., Ward, C., Tucker, C., \& Obeid, I. 2017. Performance analysis of a generalised motion capture system using Microsoft Kinect 2.0. Biomedical Signal Processing and Control, 38, 265-280.
[29] Tanaka, R., Takimoto, H., Yamasaki, T., \& Higashi, A. 2018. Validity of time series kinematical data as measured by a markerless motion capture system on a flatland for gait assessment. Journal of Biomechanics, 71, 281285.

[30] Wochatz, M., Tilgner, N., Mueller, S., Rabe, S., Eichler, S., John, M., Voller, Heinz., \& Mayer, F. 2019. Reliability and validty of the Kinect v2 for the assessment of lower extremity rehabilitation exercises. Gait and Posture, 70, 330-335. 